\title{
LITTLE HELPERS
}

\section{Dear Reader,}

They were the dominant theme at this year's IAA Commercial Vehicles: advanced driver assistance systems. After all, it won't be in passenger cars that these electronics will first become mandatory. Quite the contrary: according to EU legislation, newly registered commercial vehicles will have to be fitted with them in a year's time. From 1 November 2013, it will be a legal requirement for all newly developed trucks weighing more than $8 \mathrm{t}$ to be equipped with an Emergency Brake Assist system. In addition, a Lane Departure Warning system will be mandatory for all light trucks weighing more than $3.5 \mathrm{t}$. This new legislation was triggered by horrendous tail-end collisions at the ends of motorway traffic jams.

And it is set to become even stricter. From 2015 and 2016 respectively, the legislation will apply to all commercial vehicles which are newly registered. Suppliers such as Continental, TRW and Wabco already have fully developed systems in their product portfolio, or have succeeded in signing contracts to supply truck manufacturers.

Do you know how many assistance systems there are? Continental puts the figure at 30 , but more are imaginable. Depending on the requirements of the OEM, these safety and assistance functions can already be offered today, and they range from Active Rollover Protection, Trailer Stability Assist, Hill Start Assist and Full Speed Range Adaptive Cruise Control systems to complex, overlay functions for autonomous driving. Without doubt, these systems are aimed more at passenger cars, where their special features can be seen as a USP for the potential car buyer. By contrast, the operator of a fleet of commercial vehicles will be much more interested in whether an assistance system has the right cost-benefit ratio for him, and not necessarily for his drivers.
But how can these 30 assistance systems, which are usually part of a vehicle's active safety equipment, be reliably tested? As far as passive safety with airbags, seatbelts etc. is concerned, standardised test procedures such as FMVSS and EuroNcap have been established for years. Such standardisation has yet to be introduced for active safety. Preliminary work on solving the problem is being carried out by Aschaffenburg University of Applied Sciences together with several partners in its research project called Constant. On page 4, it discusses which methods of automated functional testing in road tests are sensible.

Even sports cars in which a sense of purism used to rule out any kind of control unit are meanwhile making intensive use of assistance systems. How an intelligent driving strategy and information on the route ahead can result in a $10 \%$ reduction in fuel consumption in the Porsche 911 and Panamera is described by Porsche on page 8 . They show that these little electronic "helpers" can combine sports car fun with saving fuel.

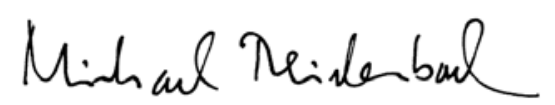

DIPL.-ING. MICHAEL REICHENBACH,

Vice-Editor in Chief

Wiesbaden, 27 September 2012

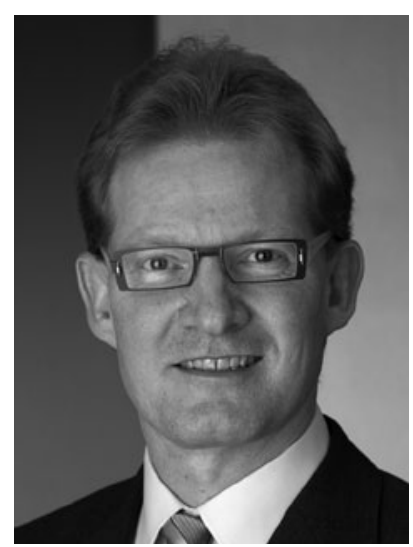

